\title{
COX6B1 relieves hypoxia/reoxygenation injury of neonatal rat cardiomyocytes by regulating mitochondrial function
}

\author{
Wei Zhang $\cdot$ Yu Wang $\cdot$ Junzhe Wan $\cdot$ Pengbo Zhang $\cdot$ Fei Pei
}

Received: 17 July 2018/Accepted: 4 October 2018/Published online: 11 October 2018

(C) The Author(s) 2018

\begin{abstract}
Objective Mitochondrial dysfunction plays a pivotal role in various pathophysiological processes of heart. Cytochrome oxidase subunit 6B1 (COX6B1) is a subunit of cytochrome oxidase.

Methods Cardiomyocytes were isolated from neonatal SD rats (within $24 \mathrm{~h}$ of birth) by repeating digestion of collagenase and trypsin. COX6B1 over-expression and hypoxia/reoxygenation was conducted on neonatal rat cardiomyocytes. Cell viability, apoptosis rates, mitochondria membrane potential and mitochondrial permeabilization transition pores (mPTPs) were then determined respectively by Cell performing Counting Kit-8 (CCK-8), Annexin-V/PI assay, JC-1 assay, $\mathrm{mPTP}$ assay. The expression of cyto $\mathrm{C}$ and apoptosis-related factors were detected by RT-Qpcr and Western blot.

Results Hypoxia/reoxygenation increased apoptosis and mPTP levels, and decreased mitochondria membrane potential in $\mathrm{I} / \mathrm{R}$ and $\mathrm{I} / \mathrm{R}+\mathrm{EV}$ groups. COX6B1 over-expression increased mitochondria cyto $\mathrm{C}$, pro-
\end{abstract}

W. Zhang · Y. Wang · J. Wan · F. Pei $(\varangle)$

Department of Cardiovascular Surgery, The Second Affiliated Hospital of Xi' an Jiaotong University, No.157

West 5 Road, Xi' an 710004, Shaanxi Province, China e-mail: feip_peifx@163.com

P. Zhang

Department of Anesthesiology, The Second Affiliated Hospital of Xi'an Jiaotong University, No.157 West 5

Road, Xi'an 710004, Shaanxi Province, China caspase-3, pro-caspase-9 and bcl-2, while it decreased cytosol cyto C, cleaved-caspase-3, cleaved-caspase- 9 and bax compared to $\mathrm{I} / \mathrm{R}+\mathrm{EV}$ group.

Conclusion COX6B1 protected cardiomyocytes from hypoxia/reoxygenation injury by reducing ROS production and cell apoptosis, during which reduction of the release of cytochrome $\mathrm{C}$ from mitochondria to cytosol was involved. Our study demonstrated that COX6B1 may be an candidate target gene in preventing hypoxia/reoxygenation injury of cardiomyocytes.

Keywords Cardiomyocytes - COX6B1 - Hypoxia/ reoxygenation injury $\cdot$ Mitochondria

\section{Introduction}

The incidence of acute myocardial infarction (AMI) is increasing annually, it has become a public health problem (Liakos and Parikh 2018; Rahman et al. 2018). The most effective therapeutic method for treating AMI is to achieve a complete reperfusion of myocardial tissue based on the opening of the coronary arteries, that is, the realization of myocardial microcirculation and reperfusion (Deng et al. 2018). Thus, preventing reperfusion injury and improving myocardial tissue reperfusion awaits to be properly solved (Asif and Morales 2018; Jakl et al. 2014). Simply restoring pericardial coronary blood flow is not sufficient in treating myocardial ischemia (Panagiotou 
et al. 2018). Effective cell protective methods should therefore be taken to reduce apoptosis and necrosis of myocardial cells (Sugiyama et al. 2018). Thus, a Full understanding of the mechanism of myocardial reperfusion injury is a prerequisite for exploring new treatment methods.

Mitochondrial dysfunction plays a pivotal role in various pathophysiological conditions including myocardial ischemia-reperfusion (I/R) injury (Feng et al. 2017; Kanaan and Harper 2017) in the heart. A large number of studies have shown that myocardial I/R could cause structural and functional abnormalities of mitochondria, which would lead to impairments of other organelles and cell homeostasis, and therefore further aggravate myocardial injury (Wang et al. 2015b; Maneechote et al. 2017). Myocardial injury can lead to not only the opening of a large number of mitochondrial permeabilization transition pores (mPTPs), but also the disruption of the mitochondrial outer membrane, thereby resulting in the release of cytochrome $\mathrm{c}$ from the mitochondrial intermembrane space and leading to increased apoptosis (Zhou et al. 2014; Wiczer et al. 2014; Kumazawa et al. 2014). Mitochondria-initiated apoptosis and necrosis are two major factors causing cell death during myocardial reperfusion (Dalla Via et al. 2014). Apoptosis can affect myocardial infarct size, and the increase of apoptosis rate will aggravate I/R damage. However, an effective inhibition of apoptosis can relieve myocardial injury (Yao et al. 2015; Deng et al. 2015; Liu 2014). Therefore, a better understanding of these complex mechanisms associated with mitochondrial dysfunction is a prerequisite for exploring novel potential therapeutic targets for maintaining mitochondrial function and cellular activity in hearts with reperfusion.

Mitochondrial disease is mainly related to Cytochrome oxidase (COX) deficiency (Popovic 2013). COX belong the cytochrome system in cellular respiration. The role of $\mathrm{COX}$ is to transfer the electrons of the respiratory substrate directly to molecular oxygen via cytochrome system (Kemppainen et al. 2014). Cytochrome oxidase subunit 6B1 (COX6B1) is one of two small subunits in the 6th subunit of cytochrome oxidase, and the main role of COX6B1 protein is to connect two COX monomers to form a dimer. Abnormal changes of COX6B1 affect greatly the function of cytochrome oxidase, and it could lead to the development of some diseases, for example, brain myopathy (Abdulhag 2015; Kim 2015; Massa 2008).

Thus, we determined to conduct a research on the functional mechanism of COX6B1 in myocardial I/R injury. This study provides novel targets to the treatment of I/R injury.

\section{Materials and methods}

\section{Animals}

Ten female breeding Sprague-Dawley (SD) rats (8-10 weeks old; $25-28 \mathrm{~g}$ of weight) were purchased from Beijing Vital River Company (Beijing, China), and under a shift of $12 \mathrm{~h}$ light/12 h dark, the rats were kept at $25{ }^{\circ} \mathrm{C}$. The animals were bred and used under the approval of Animal Management Committee of Xi'an Jiaotong University (Approval No.: AD20172650424). After the neonatal rats were born, they (within $24 \mathrm{~h}$ of birth) were used for cardiomyocytes extraction. $75 \%$ ethanol was used to disinfect the skin, and the heart was taken out. After large blood vessels adhered to the surface of the heart and the atria were cut off, the heart tissues were digested using collagenase and $0.05 \%$ trypsin at $37{ }^{\circ} \mathrm{C}$ for $10 \mathrm{~min}$ (repeated for 5 times). The supernate was then cultured by DMEM with $10 \%$ FBS for $48 \mathrm{~h}$, and cell morphology and pulsatility of obtained cardiomyocytes were observed by inverted microscope.

\section{Cell transfection}

Recombinant plasmid of COX6B1 was constructed using pcDNA3.1 Vector (Promega, USA), and transfected to myocardial cells using transfection reagent lipofectamine 3000 (Invitrogen, Carlsbad, CA, USA), and in this way, COX6B1 over-expression cells (COX6B1 group) was formed. The empty vector was transfected to myocardial cells as negative control (EV group), while myocardial cells with non-treatment were used as control (Control group). Cells were inoculated in DMEM culture media without antibiotic. When the cells reached $70 \%-80 \%$ confluence, the plasmid and lipofectamine 3000 (1:2) were added into DMEM culture media without serum, and the cells were then cultured for $6 \mathrm{~h}$. Next, the cells were cultured at $37{ }^{\circ} \mathrm{C}$ for $48 \mathrm{~h}$ in an incubator with $5 \%$ 
$\mathrm{CO}_{2}$. Cell transfection rates were detected by RTqPCR and Western blot.

Hypoxia/reoxygenation injury (I/R) injury of myocardial cells

Serum and sugar-free DMEM medium was used as hypoxic fluid replacement medium, and cardiomyocytes of Control, EV and COX6B1 groups were incubated in a closed hypoxic incubator $\left(95 \% \mathrm{~N}_{2}\right.$ and $5 \% \mathrm{CO}_{2}$ ) at $37{ }^{\circ} \mathrm{C}$ for 8 h. $95 \% \mathrm{~N}_{2}$ and $5 \% \mathrm{CO}_{2}$ mixed gas was vented at a flow rate of $2 \mathrm{~L} / \mathrm{min}$ to replace the air in the incubator. After the cells had been hypoxed, fresh DMEM medium (with 0.5\% FBS) was replaced and then cells were cultured at $37{ }^{\circ} \mathrm{C}$ with $5 \% \mathrm{CO}_{2}$ for $16 \mathrm{~h}$.

\section{Cell viability assay}

Cell counting kit 8 (CCK8; Beyotime, Nantong, China) was performed to detect cell viabilities in Control, EV, COX6B1, I/R, I/R + EV and I/R + COX6B1 groups. Cells were seeded in a 96-well plate at the concentration of $5 \times 10^{3}$ cells/well and cultured for 12 or $24 \mathrm{~h}$. Then $20 \mu \mathrm{L}$ CCK- 8 reagent was added and incubated with the cells for $1 \mathrm{~h}$. Optical density (OD) values were observed at $450 \mathrm{~nm}$ using a microplate reader (Thermo, USA).

\section{Cell apoptosis assay}

Annexin-V/PI double-stain kit (Roche, Switzerland) was used to determine cell apoptosis in Control, EV, COX6B1, I/R, I/R + EV and I/R + COX6B1 groups. Cells were seeded in a 96-well plate at the concentration of $5 \times 10^{3}$ cells/well, and stained by $5 \mu \mathrm{L}$ Annexin- $\mathrm{V}$ and $5 \mu \mathrm{L}$ PI in the dark for $5 \mathrm{~min}$ at room temperature. The analysis was immediately conducted using a flow cytometer (BD, San Diego, USA) and Cell Quest software.

Mitochondrial membrane potential assay

Mitochondrial membrane potential assay kit with JC-1 (Beyotime, China) was used to determine mitochondrial membrane potential in Control, EV, COX6B1, $\mathrm{I} / \mathrm{R}, \mathrm{I} / \mathrm{R}+\mathrm{EV}$ and $\mathrm{I} / \mathrm{R}+\mathrm{COX} 6 \mathrm{~B} 1$ groups. Cells were cultured in 24-well plates at an initial density of $5 \times 10^{5}$ cells/well and reacted with $\mathrm{JC}-1$ probe $\left(10 \mu \mathrm{mol} / \mathrm{L}\right.$ reaction concentration) at $37^{\circ} \mathrm{C}$ for $20 \mathrm{~min}$. The analysis was conducted by a flow cytometer (BD, San Diego, USA) and Cell Quest software.

Mitochondria isolation

Mitochondria were isolated from cardiomyocytes (in Control, EV, COX6B1, I/R, I/R + EV and I/R + COX6B1 groups) using Cell Mitochondria Isolation Kit (Beyotime, China). The cells were centrifuged at $4{ }^{\circ} \mathrm{C}$, at $1500 \times g$, for $10 \mathrm{~min}$. The mitochondriacontaining precipitate was then collected, and the supernatant was centrifuged at $4{ }^{\circ} \mathrm{C}$, at $1000 \times g$ for $10 \mathrm{~min}$ in order to obtain cytoplasmic proteins with non-mitochondria. The protein content of mitochondria and cytoplasmic proteins were detected in a microplate reader (wavelength of $595 \mathrm{~nm}$ ) using Bradford Protein Concentration Assay Kit (Beyotime, China).

\section{MPTP assay}

MPTP colorimetric assay kit (Genome, China) was used for mPTP detection, and $20 \mu \mathrm{L}$ mitochondrial samples (in Control, EV, COX6B1, I/R, I/R + EV and $\mathrm{I} / \mathrm{R}+\mathrm{COX} 6 \mathrm{~B} 1$ groups) were pipetted into the corresponding wells of a 96-well plate. After adding $170 \mu \mathrm{L}$ buffer, cells were immediately placed in a microplate reader (wavelength of $540 \mathrm{~nm}$ ). Then $10 \mu \mathrm{L}$ inducing solution was added in, and the cells were immediately placed in the microplate reader (wavelength of $540 \mathrm{~nm}$ ). Change at $18 \mathrm{~min}$ was obtained. The absorbance ratio (A540/Initial A540) was calculated to indicate mPTP opening condition.

\section{Western blot}

Proteins, including Mitochondria cyto c, Cytosol cyto c (cytochrome c), COX, Pro-Caspase-3, CleavedCaspase-3, Pro-Caspase-9, Cleaved-Caspase-9, Bcl-2 and Bax, were detected using sodium dodecyl sulfatepolyacrylamide gel electrophoresis (SDS-PAGE), with all lanes being loaded with $20 \mu \mathrm{g}$ protein/lane. Next, the separated proteins were electroblotted to a polyvinylidene fluoride (PVDF) membrane (Millipore, USA), which were blocked with $5 \%$ non-fat dry milk at $37{ }^{\circ} \mathrm{C}$ for $1 \mathrm{~h}$. The membrane was probed with specific primary antibodies (Abcam, USA) overnight 
at $4{ }^{\circ}$ Cand then with HRP-conjugated secondary antibodies (Abcam, USA). The immunoreactive bands were then detected by enhanced chemiluminescense (ECL) reagents (Millipore, USA). $\beta$-actin was used as loading control. Finally, the protein densities were quantified by densitometry (Bio-Rad, USA).

Realtime-quantitative polymerase chain reaction (RT-qPCR)

The mRNA expression levels of apoptosis-related factors such as Bcl-2 (B cell lymphoma/leukmia-2) and Bax (Bcl-2 associated X protein) in Control, EV, COX6B1, I/R, I/R + EV and I/R + COX6B1 groups were determined by RT-PCR. First, total RNA was extracted using RNeasy kit (Qiagen, USA). $1 \mu \mathrm{g}$ RNA was then reversely transcribed to cDNA using Highcapacity cDNA Reverse Transcription Kit (Applied Biosystems, USA). Next, PCR amplification programs was performed at $95{ }^{\circ} \mathrm{C}$ for $30 \mathrm{~s}, 40$ cycles (at $95{ }^{\circ} \mathrm{C}$ for $25 \mathrm{~s}$; at $60{ }^{\circ} \mathrm{C}$ for $25 \mathrm{~s}$; at $72{ }^{\circ} \mathrm{C}$ for $30 \mathrm{~s}$ ) using Fast SYBR Green Master Mix (Applied Biosystems, USA) in ABI 7300 Thermocycler (Applied Biosystems, USA). The primer sequences were listed in Table 1.

\section{Statistical assay}

Data were shown as mean \pm standard deviations (mean \pm SD). SPSS 18.0 statistical software was used for statistical analysis one-way analysis of variance (ANOVA) with Turkey test was used to compared the differences. $\mathrm{P}<0.05$ was considered as significantly difference. All experiments were repeated at least for three times.

Table 1 The primers applied in the study

\begin{tabular}{lll}
\hline Name & Type & Sequence $\left(5^{\prime}-3^{\prime}\right)$ \\
\hline$\beta$-actin & Forward & GTGGACATCCGCAAAGAC \\
& Reverse & GAAAGGGTGTAACGCAACT \\
COX6B1 & Forward & AACTGCTGGCAGAACTACCTGG \\
& Reverse & AGAGGGACTGGTACACACGCTG \\
Bax & Forward & AACATGGAGCTGCAGAGGAT \\
& Reverse & CCAATGTCCAGCCCATGATG \\
Bcl-2 & Forward & TTCTTTGAGTTCGGTGGGGT \\
& Reverse & CTTCAGAGACAGCCAGGAGA \\
\hline
\end{tabular}

\section{Results}

The cardiomyocytes of neonatal rats were isolated

The cardiomyocytes of neonatal rats, with certain proliferation ability, were isolated from the neonatal SD rats (within $24 \mathrm{~h}$ of birth) by repeated digestion of collagenase and trypsin. After being cultured for $48 \mathrm{~h}$, the cardiomyocytes were observed under inverted microscope with 200-fold and 400-fold magnification. The results showed that some of the cardiomyocytes were adhered to the particulate-like rough substances (Fig. 1).

COX6B1 was over-expressed in cardiomyocytes transfected with COX6B1

COX6B1 was transfected to cardiomytocytes of neonatal rats in order to construct COX6B1 overexpression cell model. By measuring the mRNA and protein levels of COX6B1, the transfection efficiency was detected using RT-qPCR and Western blot. The results demonstrated thatboth the mRNA and protein levels of COX6B1 were significantly up-regulated in COX6B1 group, compared with Control group (P $<0.01$, Fig. 2).

COX6B1 over-expression inhibited apoptosis

and enhanced mitochondrial function

in cardiomyocytes of neonatal rats with $\mathrm{I} / \mathrm{R}$

$\mathrm{I} / \mathrm{R}$ injury was created on cardiomyocytes of neonatal rats, and the cells were transfecdted with COX6B1 or empty vector. CCK-8 assay showed that I/R significantly inhibited cell viability of cardiomyocytes in $\mathrm{I} / \mathrm{R}$ and $\mathrm{I} / \mathrm{R}+\mathrm{EV}$ groups at 12 and $24 \mathrm{~h}$, and that cell viability was slightly promoted by COX6B1 overexpression compared to I/R injury (Fig. 3a). Apoptosis rates were significantly increased by $I / R$ in $I / R$, $\mathrm{I} / \mathrm{R}+\mathrm{EV}$ and $\mathrm{I} / \mathrm{R}+\mathrm{COX} 6 \mathrm{~B} 1$ groups, however, COX6B1 over-expression significantly decrease the apoptosis rates in $\mathrm{I} / \mathrm{R}+\mathrm{COX} 6 \mathrm{~B} 1$ group, compared with $\mathrm{I} / \mathrm{R}+\mathrm{EV}$ group (Fig. 3b, e). Mitochondria membrane potentials were significantly decreased by $\mathrm{I} / \mathrm{R}$ in $\mathrm{I} / \mathrm{R}, \mathrm{I} / \mathrm{R}+\mathrm{EV}$ and $\mathrm{I} / \mathrm{R}+\mathrm{COX} 6 \mathrm{~B} 1$ groups, by contrast, COX6B1 over-expression significantly increase the mitochondrial membrane potentials in $\mathrm{I} / \mathrm{R}+\mathrm{COX6B} 1$ group, compared with $\mathrm{I} / \mathrm{R}+\mathrm{EV}$ group (Fig. 3c, f). The mPTP levels were noticeably 

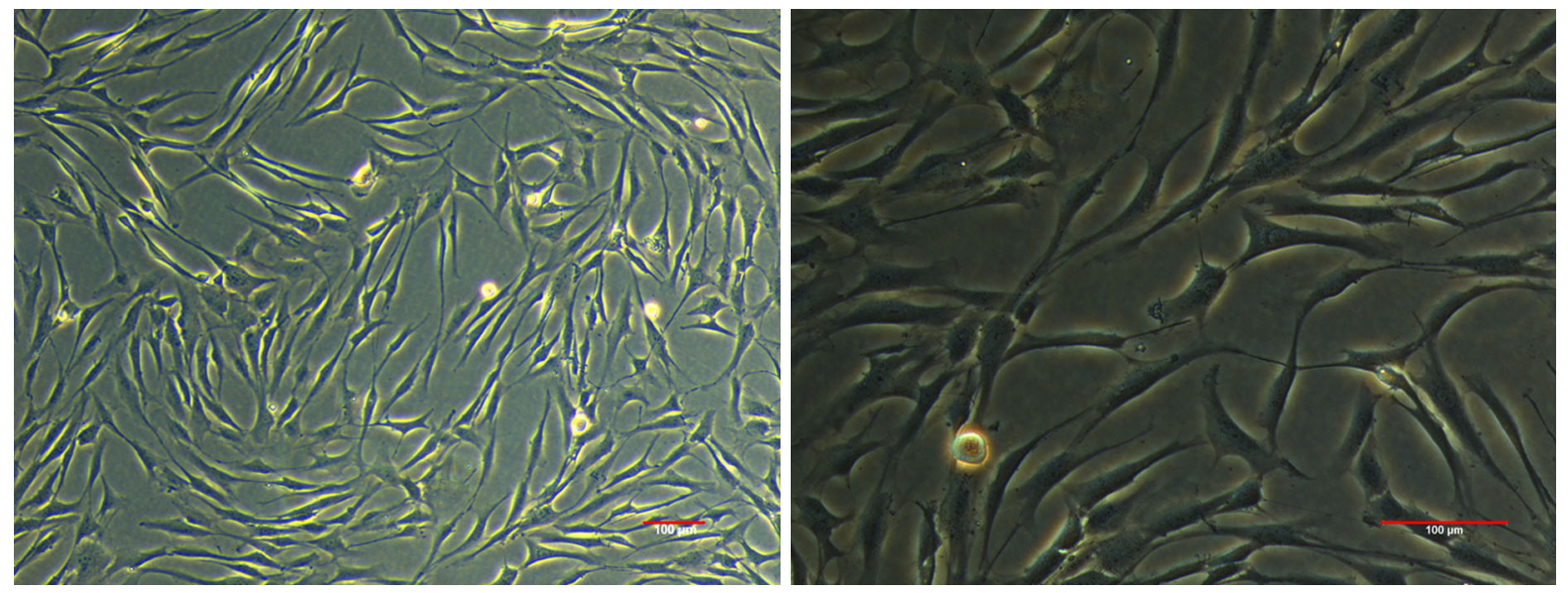

Fig. 1 The cardiomyocytes of neonatal rats were isolated and authenticated under microscope with 200-fold and 400-fold magnification

A

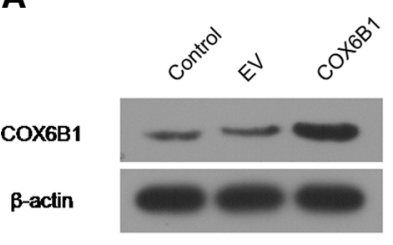

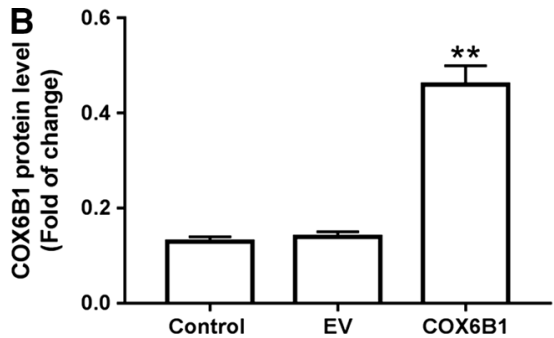

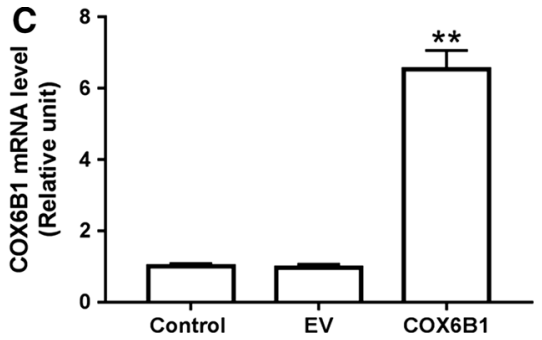

Fig. 2 COX6B1 was over-expressed in cardiomyocytes transfected with COX6B1. a, b The protein level of COX6B1 was significantly up-regulated in COX6B1 group. c The mRNA expression of COX6B1 was significantly up-regulated in COX6B1 group. $* * \mathrm{P}<0.01$ versus Control group

expression of cytosol cyto c but inhibited the expression of mitochondrial cyto c compared to $\mathrm{I} / \mathrm{R}$ and I/R + EV groups (Fig. 4).

COX6B1 over-expression inhibited cell apoptosis by regulating apoptosis-related factors in cardiomyocytes of neonatal rats with $\mathrm{I} / \mathrm{R}$

Data from Western blot data showed that the expression levels of activated Cleaved-Caspase-3 and Cleaved-Caspase-9 were noticeably down-regulated in $\mathrm{I} / \mathrm{R}$ and $\mathrm{I} / \mathrm{R}+\mathrm{EV}$ groups, compared with $\mathrm{I} / \mathrm{R}+$ COX6B1 group (Fig. 5a, c, e). Meanwhile, the expression levels of Pro-Caspase-3 and Pro-Caspase9 were significantly down-regulated in $\mathrm{I} / \mathrm{R}$ and $\mathrm{I} / \mathrm{R}+$ EV groups, compared with Control group. By contrast, a significant up-regulation of the expression levels of Pro-Caspase-3 and Pro-Caspase-9 by COX6B1 over-expression was observed in $\mathrm{I} / \mathrm{R}+$ COX6B1 group (Fig. 5a, b, d). In addition, both the COX IV levels among all detected groups was observed. COX6B1 over-expression promoted the 

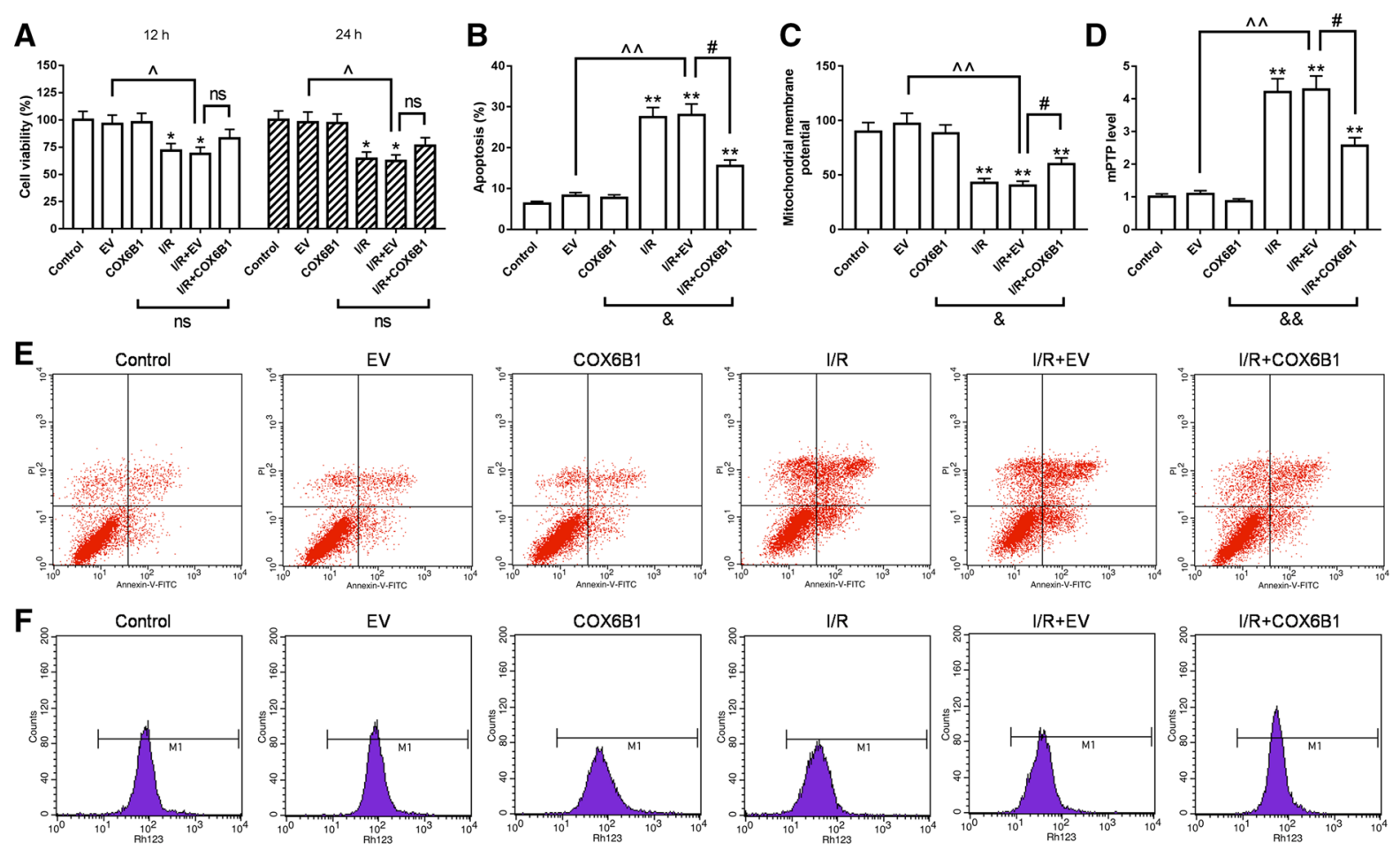

Fig. 3 COX6B1 over-expression inhibited apoptosis and enhanced mitochondrial function in cardiomyocytes of neonatal rats with I/R. a Cell viability was slightly promoted by COX6B1 over-expression in $\mathrm{I} / \mathrm{R}+\mathrm{COX} 6 \mathrm{~B} 1$ group. $\mathbf{b}$ and $\mathbf{e}$ Apoptosis rates were significantly decreased by COX6B1 over-expression in $\mathrm{I} / \mathrm{R}+\mathrm{COX6B1}$ group. $\mathbf{c}$ and $\mathbf{f}$ Mitochondria membrane potentials were significantly increased by COX6B1 over-

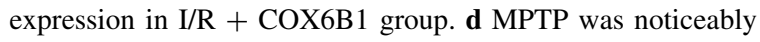
decreased by COX6B1 over-expression in $\mathrm{I} / \mathrm{R}+\mathrm{COX} 6 \mathrm{~B} 1$ group. $* \mathrm{P}<0.05$ and $* * \mathrm{P}<0.01$ versus Control group, ${ }^{\wedge} \mathrm{P}<0.05$ and ${ }^{\wedge} \mathrm{P}<0.01$ versus $\mathrm{EV}$ group, ${ }^{\#} \mathrm{P}<0.05$ versus $\mathrm{I} / \mathrm{R}+\mathrm{EV}$ group. ${ }^{\&} \mathrm{P}<0.05$ and ${ }^{\& \&} \mathrm{P}<0.01$ versus COX6B1 group

A

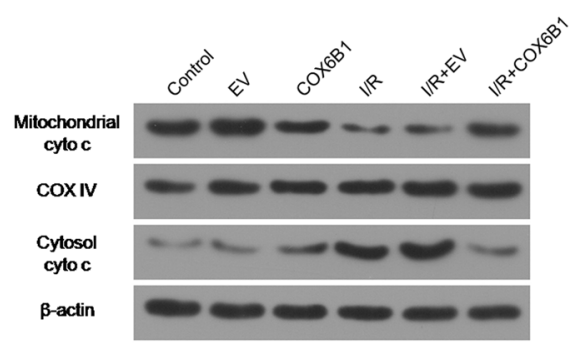

B

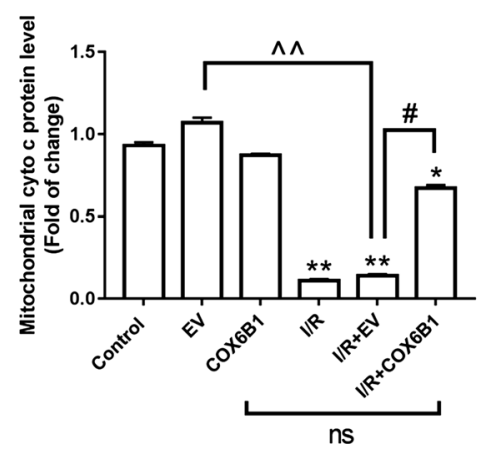

C

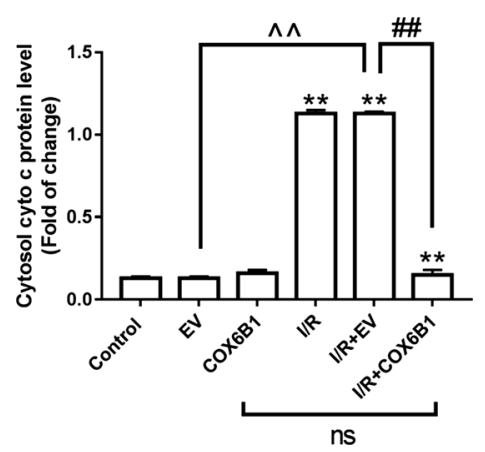

Fig. 4 COX6B1 over-expression inhibited the release of cyto $\mathrm{C}$ from mitochondria to cytoplasm in cardiomyocytes of neonatal rats with I/R. a-c Mitochondrial cyto $c$ was significantly promoted, and Cytosol cyto c was significantly inhibited by

mRNA and protein levels of Bax was significantly upregulated in $\mathrm{I} / \mathrm{R}$ and $\mathrm{I} / \mathrm{R}+\mathrm{EV}$ groups, compared with Control group, but significantly down-regulated by
COX6B1 over-expression in $\mathrm{I} / \mathrm{R}+\mathrm{COX} 6 \mathrm{~B} 1$ group. COX served as an internal control for mitochondrial protein. $* * \mathrm{P}<0.01$ versus Control group, ${ }^{\wedge \wedge} \mathrm{P}<0.01$ versus $\mathrm{EV}$ group, ${ }^{\# \#} \mathrm{P}<0.01$ versus $\mathrm{I} / \mathrm{R}+\mathrm{EV}$ group

COX6B1 over-expression in $\mathrm{I} / \mathrm{R}+\mathrm{COX6B} 1$ group (Fig. 5a, f, h). Meanwhile, both the mRNA and protein levels of Bcl-2 were significantly down-regulated in 

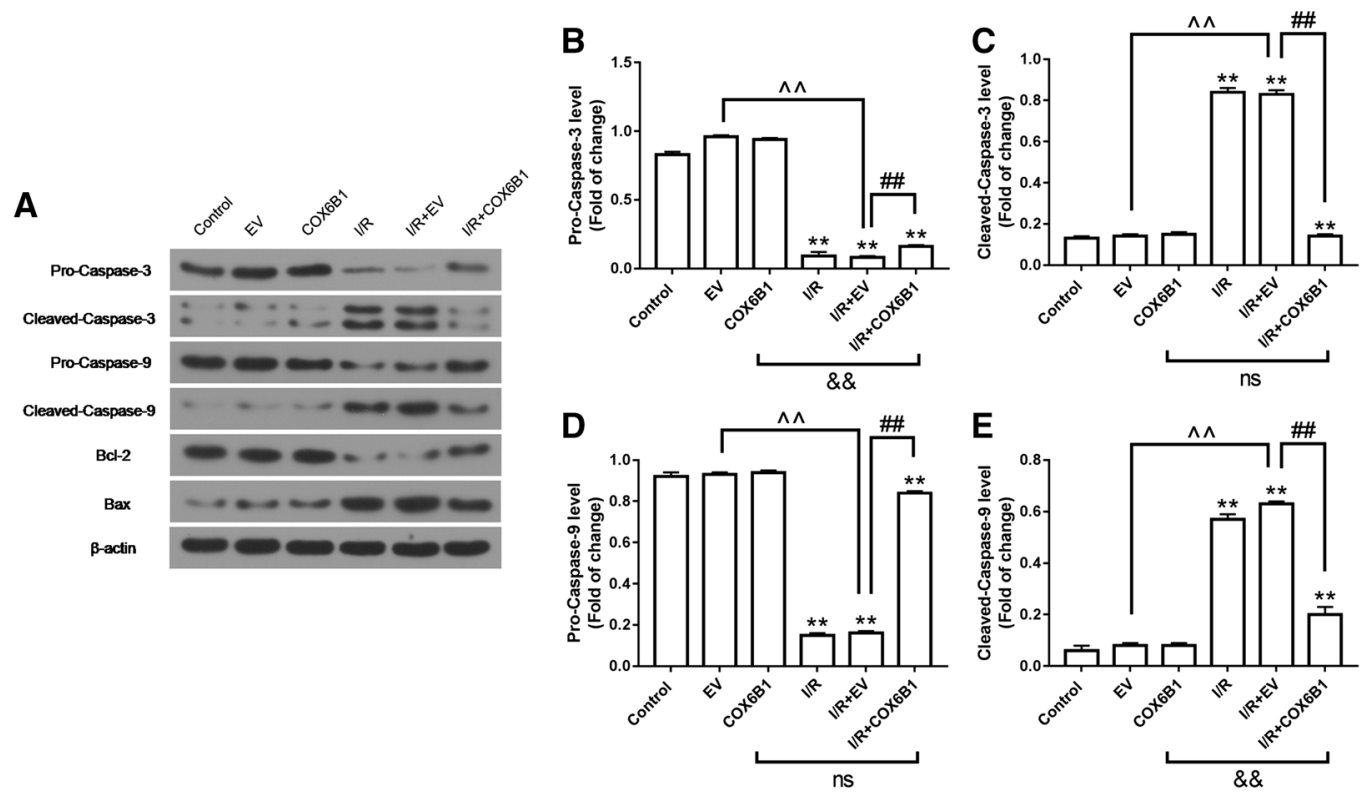
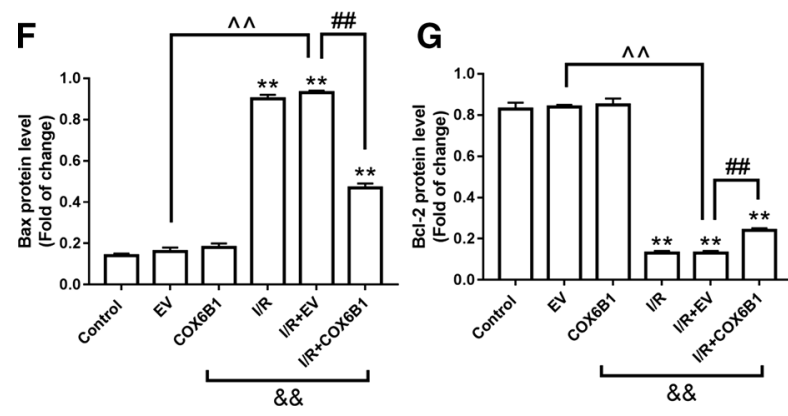

Fig. 5 COX6B1 over-expression inhibited cell apoptosis by regulating apoptosis-related factors in cardiomyocytes of neonatal rats with $I / R$. (A-G) The protein levels of CleavedCaspase-3, Cleaved-Caspase-9 and Bax were significantly down-regulated, and levels of Pro-Caspase-3, Pro-Caspase-9 and $\mathrm{Bcl}-2$ were significantly up-regulated by $\mathrm{COX} 6 \mathrm{~B} 1$ over-

$\mathrm{I} / \mathrm{R}$ and $\mathrm{I} / \mathrm{R}+\mathrm{EV}$ groups, compared with Control group, but noticeably up-regulated by COX6B1 overexpression in I/R + COX6B1 group (Fig. 5a, g, i).

\section{Discussion}

Cardiomyocytes are the most important functional cells in the heart (Geng et al. 2018). When being cultured in vitro, cardiomyocytes could maintain a variety of original cellular structures and functions, for example, spontaneous rhythm (Riching et al. 2018). This provides an excellent in vitro model for studying various molecular mechanisms of heart.
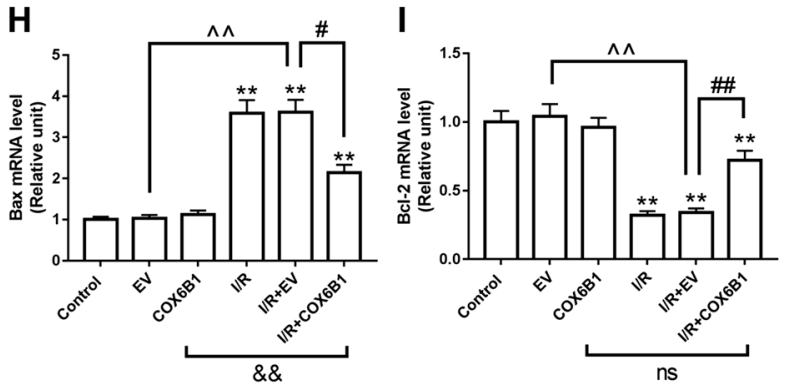

expression in $\mathrm{I} / \mathrm{R}+\mathrm{COX} 6 \mathrm{~B} 1$ group. ( $\mathrm{F}$ and $\mathrm{H}$ ) The Bax mRNA level was significantly down-regulated, and Bcl-2 mRNA level was significantly up-regulated by COX6B1 over-expression in $\mathrm{I} / \mathrm{R}+\mathrm{COX6B} 1$ group. $* * \mathrm{P}<0.01$ versus Control group, ${ }^{\wedge} \mathrm{P}<0.01$ versus EV group, ${ }^{\#} \mathrm{P}<0.05$ and ${ }^{\# \#} \mathrm{P}<0.01$ versus $\mathrm{I} / \mathrm{R}+\mathrm{EV}$ group. ${ }^{\& \&} \mathrm{P}<0.01$ versus COX6B1 group

Cardiomyocyte culture has become a basic method for investigating cardiac physiology and pathology, and it provides an ideal model for the study of heart development, differentiation, and metabolism (Boogerd et al. 2018). Therefore, the cultivation of cardiomyocytes has gradually become a useful model for studying myocardial injury (Liu et al. 2018). In this study, one-day-old neonatal rats were selected for the research, and the cardiomyocytes had strong reproductive abilities. Primary cultured neonatal rat cardiomyocytes were successfully obtained by continuous digestion of trypsin and collagenase, and a myocardial hypoxia/reoxygenation model was established to simulate an injury environment of 
cardiomyocytes after I/R injury. Our data confirmed that COX6B1 overexpression could significantly reduce the apoptosis rates of cardiomyocytes after hypoxia/reoxygenation, and that it had a significant mitochondrial protective effect, which protected cardiomyocytes from hypoxia/reoxygenation injury.

A large number of studies have confirmed that ischemia and hypoxia not only lead to necrosis, but also induce apoptosis of cardiomyocytes. Apoptosis has a profound effect on the myocardium, and inhibition of apoptosis can relieve myocardial damage (Breglia et al. 2018; Wang et al. 2018a). Our results show that over-expression of COX6B1 could effectively restrain cell apoptosis during myocardial ischemia. Apoptosis is a type of programmed cell death that is regulated by a series of genes (El-Gamal and Gouida 2013). Among those genes, Bcl-2 gene is the first identified apoptosis-inhibiting gene (Pan et al. 2014). Bcl-2 protein is mainly distributed in the inner mitochondrial membrane, and its high expression can inhibit apoptosis caused by a variety of factors (Bittremieux et al. 2018). Bax is the most important apoptosis-promoting factor in Bcl-2 family (Wang et al. 2018b). Mitochondrial pathway is alternatively known as endogenous apoptotic pathway, and it is one of the most important pathways for apoptosis (Wang et al. 2015a). Massive opening of mPTP is a primary cause that induces cell apoptosis (Fakharnia et al. 2017). By regulating the opening of $\mathrm{mPTP}, \mathrm{Bcl}-2$ family proteins are the key regulatory factors of this pathway (Chen et al. 2015). Our study found that in the hypoxia-reoxygenation model of myocardiocytes, mPTP was mostly opened and could laed to the disruption of mitochondrial outer membrane. Therefore, mitochondrial membrane potential was reduced, leading to the release of pro-apoptotic factors, such as cytochrome $\mathrm{c}$, from the mitochondrial intermembrane space. The concentration of cytochrome $\mathrm{C}$ in the cytoplasm increased significantly, while cytochrome $\mathrm{C}$ in the mitochondria decreased significantly. The extravasated cytochrome $\mathrm{c}$ activates Caspase-9, which in turn cleaves Caspase- 3 to be its active subunit (Wen et al. 2014). Activated Caspase- 3 has an ability of cleaving peptide bonds after an aspartate residue, and this would result in the degradation and inactivation of intracellular important proteins, DNA fragmentation, and apoptosis of cardiomyocytes (Zhao et al. 2014). Overexpression of COX6B1 significantly reduced the opening of $\mathrm{mPTP}$, the disruption of mitochondrial outer membranes, and cytoplasmic cytochrome $\mathrm{C}$ levels in hypoxic and reoxygenated cardiomyocytes. Meanwhile, the levels of Bax, Cleaved-caspase-3, and Cleaved-caspase- 9 were decreased and Bcl-2 level was increased, and such phenomena inhibited the apoptosis of cardiomyocytes subjected to hypoxiareoxygenation.

Myocardial cells cannot adapt quickly to hyperoxia caused by a sudden restoration of blood flow after continuous ischemia. Thus, the myocardial cells are damaged. Overexpression of COX6B1 not only inhibits mPTP opening, cell apoptosis and the mitochondrial membrane rupture of cardiomyocytes, but also reduces the release of cytochrome $\mathrm{C}$. Therefore, overexpression of COX6B1 plays a critical role in myocardial protection.

\section{Compliance with ethical standards}

Conflict of interest The authors declare no conflicts of interest.

Open Access This article is distributed under the terms of the Creative Commons Attribution 4.0 International License (http:// creativecommons.org/licenses/by/4.0/), which permits unrestricted use, distribution, and reproduction in any medium, provided you give appropriate credit to the original author(s) and the source, provide a link to the Creative Commons license, and indicate if changes were made.

\section{References}

Abdulhag UN et al (2015) Mitochondrial complex IV deficiency, caused by mutated COX6B1, is associated with encephalomyopathy, hydrocephalus and cardiomyopathy. Eur J Hum Genet 23:159-164. https://doi.org/10.1038/ ejhg.2014.85

Asif A, Morales MDP (2018) Cytomegalovirus infection in a patient with systemic lupus erythematosus and acute myocardial infarction-cause or causal relationship? J Commun Hosp Intern Med Perspect 8:123-126. https:// doi.org/10.1080/20009666.2018.1475187

Bittremieux M et al (2018) Constitutive IP3 signaling underlies the sensitivity of B-cell cancers to the Bcl-2/IP3 receptor disruptor BIRD-2. Cell Death Differ. https://doi.org/10. 1038/s41418-018-0142-3

Boogerd CJ et al (2018) Tbx20 is required in mid-gestation cardiomyocytes and plays a central role in atrial development. Circ Res. https://doi.org/10.1161/circresaha.118. 311339

Breglia A et al (2018) Determinants of Monocyte Apoptosis in Cardiorenal Syndrome Type 1. Cardiorenal Med 8:208-216. https://doi.org/10.1159/000488949 
Chen Q, Xu H, Xu A, Ross T, Bowler E, Hu Y, Lesnefsky EJ (2015) Inhibition of Bcl-2 sensitizes mitochondrial permeability transition pore (MPTP) opening in ischemiadamaged mitochondria. PLoS ONE 10:e0118834. https:// doi.org/10.1371/journal.pone.0118834

Dalla Via L, Garcia-Argaez AN, Martinez-Vazquez M, Grancara S, Martinis P, Toninello A (2014) Mitochondrial permeability transition as target of anticancer drugs. Curr Pharm Des 20:223-244

Deng L et al (2015) Histamine deficiency exacerbates myocardial injury in acute myocardial infarction through impaired macrophage infiltration and increased cardiomyocyte apoptosis Sci Rep 5:13131. https://doi.org/10.1038/ srep13131

Deng Y et al (2018) Bifunctional supramolecular hydrogel alleviates myocardial ischemia/reperfusion injury by inhibiting autophagy and apoptosis. J Biomed Nanotechnol 14:1458-1470. https://doi.org/10.1166/jbn.2018.2582

El-Gamal EM, Gouida MS (2013) Quantitative changes in p53, $\mathrm{Bcl}-2$ and apoptosis in blood and urine of bladder cancer patients. Clin Lab 59:349-358

Fakharnia F, Khodagholi F, Dargahi L, Ahmadiani A (2017) Prevention of cyclophilin D-mediated mPTP opening using cyclosporine-A alleviates the elevation of necroptosis, autophagy and apoptosis-related markers following global cerebral ischemia-reperfusion. J Mol Neurosci 61:52-60. https://doi.org/10.1007/s12031-016-0843-3

Feng Y, Madungwe NB, da Cruz Junho CV, Bopassa JC (2017) Activation of $G$ protein-coupled oestrogen receptor 1 at the onset of reperfusion protects the myocardium against ischemia/reperfusion injury by reducing mitochondrial dysfunction and mitophagy. British J Pharmacol 174:4329-4344

Geng L, Wang Z, Cui C, Zhu Y, Shi J, Wang J, Chen M (2018) Rapid electrical stimulation increased cardiac apoptosis through disturbance of calcium homeostasis and mitochondrial dysfunction in human induced pluripotent stem cell-derived cardiomyocytes. Cell Physiol Biochem 47:1167-1180. https://doi.org/10.1159/000490213

Jakl M et al (2014) Acute myocardial infarction complicated by shock: outcome analysis based on initial electrocardiogram. Scand Cardiovasc J 48:13-19. https://doi.org/10. 3109/14017431.2013.865074

Kanaan GN, Harper ME (2017) Cellular redox dysfunction in the development of cardiovascular diseases. Biochimica et Biophysica Acta General Subjects 1861:2822-2829

Kemppainen KK et al (2014) Expression of alternative oxidase in Drosophila ameliorates diverse phenotypes due to cytochrome oxidase deficiency. Hum Mol Genet 23:2078-2093. https://doi.org/10.1093/hmg/ddt601

Kim SE et al (2015) Upregulation of cytochrome c oxidase subunit 6b1 (Cox6b1) and formation of mitochondrial supercomplexes: implication of Cox6b1 in the effect of calorie restriction. Age (Dordr) 37:9787. https://doi.org/10. $1007 /$ s $11357-015-9787-8$

Kumazawa A et al (2014) Microtubule disorganization affects the mitochondrial permeability transition pore in cardiac myocytes. Circ J 78:1206-1215

Liakos M, Parikh PB (2018) Gender Disparities in presentation, management, and outcomes of acute myocardial infarction.
Curr Cardiol Rep 20:64. https://doi.org/10.1007/s11886018-1006-7

Liu Y et al (2014) AGGF1 protects from myocardial ischemia/ reperfusion injury by regulating myocardial apoptosis and angiogenesis. Apoptosis 19:1254-1268. https://doi.org/10. 1007/s10495-014-1001-4

Liu $\mathrm{Z}$ et al (2018) Nterminal truncated peroxisome proliferatoractivated receptorgamma coactivatorlalpha alleviates phenylephrineinduced mitochondrial dysfunction and decreases lipid droplet accumulation in neonatal rat cardiomyocytes. Mol Med Rep. https://doi.org/10.3892/mmr. 2018.9158

Maneechote C, Palee S, Chattipakorn SC, Chattipakorn N (2017) Roles of mitochondrial dynamics modulators in cardiac ischaemia/reperfusion injury. J Cell Mol Med 21:2643-2653. https://doi.org/10.1111/jcmm.13330

Massa V et al (2008) Severe infantile encephalomyopathy caused by a mutation in COX6B1, a nucleus-encoded subunit of cytochrome c oxidase. Am J Hum Genet 82:1281-1289. https://doi.org/10.1016/j.ajhg.2008.05.002

Pan LL, Wang AY, Huang YQ, Luo Y, Ling M (2014) Mangiferin induces apoptosis by regulating $\mathrm{Bcl}-2$ and $\mathrm{Bax}$ expression in the CNE2 nasopharyngeal carcinoma cell line. Asian Pac J Cancer Prev 15:7065-7068

Panagiotou A, Trendelenburg M, Osthoff M (2018) The lectin pathway of complement in myocardial ischemia/reperfusion injury-review of its significance and the potential impact of therapeutic interference by $\mathrm{C} 1$ esterase inhibitor. Front Immunol 9:1151. https://doi.org/10.3389/fimmu. 2018.01151

Popovic DM (2013) Current advances in research of cytochrome c oxidase. Amino Acids 45:1073-1087. https://doi.org/10. 1007/s00726-013-1585-y

Rahman H, Khan SU, Lone AN, Kaluski E (2018) Revascularization strategies in cardiogenic shock complicating acute myocardial infarction: a systematic review and metaanalysis. Cardiovasc Revasc Med. https://doi.org/10.1016/ j.carrev.2018.06.004

Riching AS, Zhao Y, Cao Y, Londono P, Xu H, Song K (2018) Suppression of pro-fibrotic signaling potentiates factormediated reprogramming of mouse embryonic fibroblasts into induced cardiomyocytes. J Vis Exp. https://doi.org/10. $3791 / 57687$

Sugiyama H, Takagi K, Morita Y, Tsuboi H, Morishima I (2018) A case of stepwise successful reperfusion with a combination of excimer laser coronary angioplasty and rivaroxaban in delayed myocardial infarction with massive thrombus. Cardiovasc Interv Ther. https://doi.org/10.1007/ s12928-018-0530-0

Wang P et al (2015a) Dynamin-related protein Drp1 is required for Bax translocation to mitochondria in response to irradiation-induced apoptosis. Oncotarget 6:22598-22612. https://doi.org/10.18632/oncotarget.4200

Wang S, Li Y, Song X, Wang X, Zhao C, Chen A, Yang P (2015b) Febuxostat pretreatment attenuates myocardial ischemia/reperfusion injury via mitochondrial apoptosis. J Transl Med 13:209. https://doi.org/10.1186/s12967-0150578-X

Wang L, Chen Z, Liu Y, Du Y, Liu X (2018a) Ozone oxidative postconditioning inhibits oxidative stress and apoptosis in renal ischemia and reperfusion injury through inhibition of 
MAPK signaling pathway. Drug Des Devel Ther 12:1293-1301. https://doi.org/10.2147/dddt.s164927

Wang M, Liu M, Ni T, Liu Q (2018b) miR214 mediates vascular inflammation and apoptosis via PTEN expression. Mol Med Rep. https://doi.org/10.3892/mmr.2018.9185

Wen Q, Zhang X, Cai J, Yang PH (2014) A novel strategy for real-time and in situ detection of cytochrome $\mathrm{c}$ and caspase-9 in Hela cells during apoptosis. Analyst 139:2499-2506. https://doi.org/10.1039/c3an02205f

Wiczer BM, Marcu R, Hawkins BJ (2014) KB-R7943, a plasma membrane $\mathrm{Na}^{(+)} / \mathrm{Ca}^{(2+)}$ exchanger inhibitor, blocks opening of the mitochondrial permeability transition pore. Biochem Biophys Res Commun 444:44-49. https://doi. org/10.1016/j.bbrc.2014.01.009
Yao $\mathrm{T}$ et al (2015) Vitamin D receptor activation protects against myocardial reperfusion injury through inhibition of apoptosis and modulation of autophagy. Antioxid Redox Signal 22:633-650. https://doi.org/10.1089/ars.2014.5887

Zhao J, Wang J, Wu J (2014) Roles of cytochrome c, caspase-9, and caspase-3 in pentavalent vanadium-induced neuronal apoptosis. Zhonghua Lao Dong Wei Sheng Zhi Ye Bing Za Zhi 32:664-667

Zhou JS et al (2014) Ginsenoside Rd attenuates mitochondrial permeability transition and cytochrome $\mathrm{C}$ release in isolated spinal cord mitochondria: involvement of kinasemediated pathways. Int J Mol Sci 15:9859-9877. https:// doi.org/10.3390/ijms15069859 